\title{
Measurement of Background Translocation Frequencies in Individuals with Clones
}

Marcelle J. Wade MS Thesis

August 1996 


\section{DISCLAIMER}

This document was prepared as an account of work sponsored by an agency of the United States Government. Neither the United States Government nor the University of California nor any of their employees, makes any warranty, express or implied, or assumes any legal liability or responsibility for the accuracy, completeness, or usefulness of any information, apparatus, product, or process disclosed, or represents that its use would not infringe privately owned rights. Reference herein to any specific commercial product, process, or service by trade name, trademark, manufacturer, or otherwise, does not necessarily constitute or imply its endorsement, recommendation, or favoring by the United States Government or the University of California. The views and opinions of authors expressed herein do not necessarily state or reflect those of the United States Government or the University of California, and shall not be used for advertising or product endorsement purposes.

This report has been reproduced directly from the best available copy.

Available to DOE and DOE contractors from the Office of Scientific and Technical Information P.O. Box 62, Oak Ridge, TN 37831

Prices available from (615) 576-8401, FTS 626-8401

Available to the public from the National Technical Information Service

U.S. Department of Commerce 5285 Port Royal Rd., Springfield, VA 22161

Work performed under the auspices of the U.S. Department of Energy by Lawrence Livermore National Laboratory under Contract W-7405-ENG-48. 


\title{
Measurement of Background Translocation Frequencies in Individuals with Clones
}

\author{
Marcelle J. Wade \\ Master of Science \\ Thesis
}

Manuscript date: August 1996

LAWRENCE LIVERMORE NATIONAL LABORATORY University of California - Livermore, California - 94551 
MEASUREMENT OF BACKGROUND TRANSLOCATION FREQUENCIES

IN INDIVIDUALS WITH CLONES

A University Thesis Presented to the Faculty

of

California state University, Hayward

In Partial Fulfillment

of the Requirements for the Degree

Master of science in Biological science

By

Marcelle J. Wade

August, 1996 


\section{ABSTRACT}

Metaphases were scored for chromosomal aberrations, specifically reciprocal translocations, using fluorescence in situ hybridization (FISH) . Metaphase spreads were used from two healthy, unexposed individuals (not exposed to radiation, chemotherapy or radiotherapy) and one early Bprecursor acute lymphocytic leukemia (ALL) patient (metaphase spreads from both separated $\mathrm{T}$ lymphocytes and unseparated B and T lymphocytes were scored).

All three individuals had an abnormally high translocation frequency. The high translocation frequencies resulted from clonal expansion of specific translocated chromosomes.

I show in this thesis that by purging (discounting or removing) clones from the data of unexposed individuals, one can obtain true background translocation frequencies. In two cases, Bio 8 and Bio 23, the measured translocation frequency for chromosomes 1,2 and 4 was $0.0124 \pm 0.0014$ and $0.0073 \pm 0.0014$, respectively. After purging all clones from the data, the translocation frequencies for Bio 8 and Bio 23 were $0.0075 \pm 0.0011$ and $0.0060 \pm 0.0012$, respectively. This in good agreement with the expected background frequencies. Finally, in the leukemia case the unseparated $B$ and $T$ lymphocytes had a high translocation frequency even after 
purging all of the clones from the data. This high translocation frequency may be due to a low frequency of some clones and may not be recognized. The separated $\mathrm{T}$ lymphocytes had a higher translocation frequency than expected. However this study is still in progress. 



\section{ACRNOWTEDGMFNTS}

I would like to thank my research advisor Dr. Joe Lucas for his help and support as well as letting me do my Master of Science thesis under his guidance at Lawrence Livermore National Laboratory. Thank you to Dr. Steve Benson (my major advisor) and Dr. Chris Baysdorfer (my advisor) for guiding me and answering my questions throughout the process of writing my thesis and helping me set the guidelines I needed. I would also like to thank Francesca Hill for her help when I needed a second pair of eyes for confirmation, and Angela Lewis for helping me double check some of the clones. Thank you to Dr. Richard Tullis for giving me the opportunity to interview and work at Lawrence Livermore National Laboratory which then allowed me to do my thesis there. 
Page

I. Abstract

ii

II. Acknowledgements

$\mathrm{v}$

III. List of Tables/Figures vii

IV. List of Plates/Photos/Graphs viii

v. Introduction 1

A. FISH (Fluorescence In Situ 4

Hybridization)

B. Chromosomal Aberrations 7

C. Genetic Effects of Radiation 11

D. Research Goal 20

VI. Methods and Materials 23

VII. Results 30

$\begin{array}{ll}\text { VIII. Discussion } & 43\end{array}$

$\begin{array}{lll}\text { IX. } & \text { References } & 48\end{array}$ 


\section{IIST OF TABLES}

\section{Rage}

I. Table 1. Data is for subjects Bio $8 \quad 33-34$ and Bio 11 (2 healthy, unexposed individuals) showing the number of reciprocal translocations and reciprocal translocation frequencies involving chromosome 2 only and chromosomes 1,2 and 4 .

II. Table 2. Data for subject Bio 11 unseparated B and T lymphocytes (early B-precursor ALL patient) showing the translocation frequencies for chromosomes 1,2 and 4 before and after purging of the clones. 


\section{LIST OF FIGURES}

\section{Page}

I. Figure 1. An example of 2 clones with 37-38 translocations from a healthy, unexposed individual (Bio 8 ).

II. Figure 2. An example of 2 clones 39-40 with translocations from a healthy, unexposed individual (Bio 23).

III. Figure 3. An example of 2 clones $41-42$ with translocations from a leukemia patient (Bio 11 unseparated). 


\section{INTRODOCTION}

Background translocation frequency is the frequency of translocations in individuals who have not been exposed to chromosome breaking (clastogenic) agents above natural background radiation. Natural background exposure (which is clastogenic) comes from external radiation from space and from the ground as well as radioisotopes and several cosmogenic radionuclides being inhaled and ingested (Harley, 1983). Though everyone on the planet receives natural radiation, some people get more than others (United Nations Environment Programme, 1991). This can result from where they live, for example: in some places where radioactivity in rocks or soils is much higher than in others (United Nations Environment Programme, 1991). Alternatively, natural background exposure can result from lifestyle, for example: using certain building materials, cooking with gas, burning open coal fires, etc. increases exposure to natural radiation (United Nations Environment Programme, 1991). Terrestrial sources are responsible for most of our exposure to natural radiation, and cosmic rays contribute to the remainder (United Nations Environment Programme, 1991).

Measuring background frequency in unexposed individuals is straightforward and can be done by simply scoring 
translocations in blood lymphocytes and calculating the frequency as translocations per total cells scored. However, this is more difficult in individuals who have cancer or who have clones involving translocations because the translocations from the cancer or from clones mask the background translocation frequency.

Background translocation frequencies are important in biological dosimetry for dose reconstruction (Lucas et al., 1995). If an individual has been or suspects that he or she has been exposed to ionizing radiation, one can compare the translocation frequency of that individual to individuals (similar in age and lifestyle) unexposed to ionizing radiation above background, chemotherapy, and radiotherapy (Dr. Joe Lucas, personal communication). If the prior exposure is above the detection limit of 0.05 to 0.1 Gray (a dose measurement), then the exposure will be detected by the increase of translocation frequencies above that of background levels (Lucas et al., 1994).

Chromosome aberration analysis has become a recognized biological method for the estimation of whole body dose and it has an important role in conjunction with physical methods in radiological protection (Dolphin et al., 1973). Accurate assessment of radiation exposure is important for the detection of exposure in one's occupation or the 
environment, for the evaluation and guidance of medical treatment when accidental exposure has occured, or for the measurement of radio-sensitivity of tumors and normal tissues to optimize cancer therapy (Vrolijk et al., 1994). clonal expansion of specific lymphocyte subsets could as a result of immunological challenge could, in principle, cause fluctuations in the measurement of translocation frequencies for irradiated individuals, which complicates the estimation of individual dose (Lucas et al., 1992).

Exposure to ionizing radiation can result in breakage and rearrangement of chromosome structure. So, chromosomal aberrations could be used as a type of biological dosimeter. Using previously determined calibration curves from relevant cells exposed to known doses, the unknown dose can be calculated. Also, chromosomal abnormalities were found to be characteristic of, and often diagnostic for, many human diseases. So, cytogenetic analysis became a widely used clinical procedure (Bender et al., 1988).

The human peripheral lymphocyte is most often used for biological radiation dosimetry. In the cell of a Go stage cell cycle, radiation exposure induces exclusively chromosome-type aberrations. "Chromosome-type" aberrations involve both chromatids identically. When the DNA double helix containing deletions or other aberrations replicates, 
these are replicated as well, which gives rise to "chromosome-type" aberrations. In contrast, exposure to most chemical agents induces exclusively chromatid-type aberrations. When the DNA has replicated, both double helices behave in general as an independant "target" which gives rise to "chromatid-type" aberrations. This involves only one or the other chromatid at any given location. ultraviolet light and the majority of the many known chemical clastogens show a different pattern where only chromatid aberrations are seen in the first mitosis after interphase exposure known as "s-dependence".

Characteristically s-dependent clastogenic agents induce few, if any chromosome type aberrations, and treated cells must go through an $s$ phase for significant aberration production (Bender et al., 1988).

\section{EI8H (Fluorescence In situ Hybridigation)}

Fluorescence in situ hybridization (FISH) with DNA probes has been shown to be a rapid method for the detection of chromosomal rearrangements, and appears to be very useful for analysis of induced translocations. In situ hybridization of chromosome-specific unique-sequence probes together with an excess of total human DNA to block hybridization of repetitive sequences, will label the whole 
length of a specific chromosome from which the probe DNA was obtained. Using an appropriate counterstain results in visualization of the unpainted chromosomes in a different color. So, a painted and unpainted chromosome involved in an exchange (e.g., a translocation) appears bicolored. Because only one or a few chromosomes are painted, only a fraction of all possible exchanges are detected. The number of metaphases examined is then adjusted according to the fraction of translocations detected for the chromosomes that are painted, which is calculated by taking into account the number of chromosomes painted as well as which chromosomes are painted. Assuming that exchange events occur randomly in all chromosomes in the genome depending on the DNA content of each chromosome, one can estimate the frequency of translocations for the whole genome (Lucas et al., 1989, pgs. 35-44, and 1992).

The type of aberrations that are detected by FISH include translocations, dicentrics, some inversions, some deletions, insertions, and complex exchanges that involve three or more breaks (Lucas et al., 1992). There are many uses for FISH; for example: Pinkel et al.(1986) demonstrate the use of FISH for (i) labeling human chromosomes in metaphase and interphase human-hamster hybrid cells, (ii) detection of interspecies translocations, (iii) labeling 
specific human chromosomes in metaphase and interphase human cells, and (iv) quantitating the amount of target DNA sequence. Savage and Simpson (1994) presented a method of classifying chromosome-type complex exchanges using FISH.

It has been shown previously that using FISH procedures (using probes from portions of the bcr and abl genes) one could detect the bcr/abl fusion event in CML (chronic myelogenous leukemia) patients with classic or variant $\mathrm{Ph}$ (Philadelphia chromosomes, simple type). The results of Chen et al., 1993 demonstrate that this FISH assay can also detect the bcr/abl fusion in CML patients with masked or variant (complex type) Ph chromosomes and in some patients with Ph posivite ALL (acute lymphocytic leukemia) or AML (acute myelocytic leukemia) (Chen et al., 1993).

A patient with acute nonlymphocytic leukemia (ANLL) showing monosomy 16 , an extra 1p-, and a $21 q+$ could not be defined by GTG-banding. A series of two-color FISH studies with chromosome-specific DNA libraries, centromere-specific repetitive DNA probes, and a band-specific YAC clone were done. The purpose was to identify the chromosomes that had contributed to the formation of the derivatives as well as the localization of the breakpoint regions (Taniwaki et al., 1993). 
The final example are FISH studies that were done on four patients with non-Hodgkin's lymphoma, one with acute lymphoblastic leukemia, one with plasma cell leukemia, and three cell lines. In order to identify the breakpoint of 14 q32 translocations in both metaphase spreads and interphase nuclei, double-color FISH was performed with bacteriophage clones containing the human Ig gamma gene and a cosmid clone variable region (VH) gene segments of the IgH locus. With this technique, 14q32 translocations were detected as separate signals of these two loci, or those of Ig gamma genes in individual tumors (Taniwaki et al., 1995).

\section{Chromosomal Aberrations}

The two major classes of chromosomal aberrations induced by ionizing radiation in human peripheral blood Go lymphocytes are unstable aberrations (dicentrics, acentric fragments, centric rings) and stable aberrations (reciprocal translocations as well as other types of translocations) (Natarajan et al., 1992). Unstable aberrations, for mechanical reasons, can be modified or lost during cell division (during mitosis when chromosomes are pulled to either side of the cell) (Bender et al., 1988). So the aberrations evident at the first metaphase following their induction can appear again in different form in subsequent 
metaphases, or they may not be evident at all (if the cell survives long enough to enter another division) (Bender et al., 1988). Translocations (as well as inversions) are stable exchange aberrations that can persist through many cell divisions, usually just as well as the normal chromosomes (Bender et al., 1988). In fact, reciprocal translocations are perfectly stable with time (Lucas et al., 1996).

Dicentric chromosomes (chromosomes with 2 centromeres) have been analyzed because they can be scored quickly without banding. However the use of dicentrics for biological dosimetry is complicated because the frequency of cells carrying dicentric chromosomes decrease with time after exposure. This is a problem when dosimetry is required for occupationally or accidentally exposed individuals because the time between exposure and analysis can be large or even unknown (Lucas et al., 1992). Scoring stable aberrations such as symmetrical translocations which do not have a selective disadvantage during cell proliferation would be a considerable advance for an improved quantification of past exposures (Schmid et al., 1992). Measurement of the low translocation frequency that is usually found in exposed humans has been too difficult and time consuming when using conventional 
staining of banding analysis to be routinely practical (Lucas et al., 1992). However, recent advances in chromosome staining using FISH facilitate these measurements (Lucas et al., 1992).

A good indicator for biological dosimetry is the frequency of dicentrics when measurements are made within a few months of irradiation (Vrolijk et al., 1994). However, as the dicentrics disappear over time with cell division and there is replenishment with new lymphocytes, the scoring of stable aberrations, i.e. translocations, is a better estimator when the exposure is chronic or analysis is carried out long after irradiation (Vrolijk et al., 1994). As translocations are stable and can be perpetuated during proliferation of cells, they are important from the genetic and cancer risk point of view (Natarajan et al., 1992).

When using FISH, aberration analysis is based on recognition of altered color patterns. Scoring painted chromosomes for translocations is fast, objective, and is learned with a minimum of training. The disadvantage of chromosome painting is that only a fraction of all exchanges are detected, so additional cells need to be scored to compensate for the smaller fraction of translocations detected. However, the increased speed of analysis of exchanges more than compensates for this (Tucker et al., 
1993).

Acute forms of leukemia (which include acute lymphocytic leukemia as well as the subtypes of acute nonlymphocytic leukemia) and chronic myelocytic leukemia have been found to be induced by radiation (Linet, 1985). A recently proposed classification for acute lymphocytic leukemia (ALL) defines four subtypes: Null cell ALL (also called early B-precursor ALL or non-B, non-T ALL); common ALL; T-cell ALL; and B-cell ALL, which seem to have somewhat different sex distributions, prognoses, and responses to treatment (Linet, 1985). The majority of ALLs have been referred to as non-B, non-T ALL (Minden, 1985). Many different monoclonal antibodies that have been developed that react with normal $B$ cells react with some blast cells of non-B, non-T ALL (Minden, 1985).

There are three ways of demonstrating the clonal nature of ALL: (i) the finding that the blast cells all contain the same immunoglobin gene rearrangement; (ii) at presentation leukemic cells often have an abnormal karyotype; (iii) and the use of the enzyme G6PD (glucose-6-phosphate dehydrogenase) (Minden, 1985 and Ferraris et al., 1985). The rearrangement of immunoglobulin genes may be involved in malignant transformation (Minden, 1985). In some leukemias and lymphomas, chromosome translocations which involve the 
exchange of material of immunoglobulin regions on chromosomes 2,14 , or 22 with a region on chromosome 8 are seen (Minden; 1985). The region on chromosome 8 involved in the translocations contain the c-myc gene which is a potential oncogene (Minden, 1985). As a result, the expression of the myc gene is altered and this, in part is felt to be responsible for the development of leukemia (Minden, 1985) - Chromosome translocations are associated with a variety of hematopoietic malignancies (Croce, 1987). Red bone marrow and the rest of the blood-forming system are affected by a radiation dose as little as 0.5 to one gray. Fortunately, the blood forming system has a remarkable capacity for regeneration, and if the dose is not too great as to overwhelm it, can recover completely from these early effects, but they will be at a higher risk of developing leukemia later in years (United Nations Environment Programme, 1991).

\section{Genetic Rffects of Radiation}

Genetic effects of radiation exposure fall into two main categories; chromosome aberrations that involve changes in the number or structure of chromosomes, and mutation of the genes themselves. Both categories of effects may cause hereditary disease in future generations. (United National 
Environment Programme, 1991).

There is evidence that people exposed to low doses of radiation do suffer detectable chromosome damage in their blood cells (United National Environment Programme, 1991). Nuclear workers that were exposed to less than the internationally accepted maximum level of radiation in the United Kingdom, Germany and the United States exhibited chromosome damage (Evans, 1979 and United National Environment Programme, 1991).

Ionizing radiation consists mainly of electromagnetic waves that remove or add charges to electrically neutral atoms or molecules. There are different kinds of ionizing radiation which includes $x$ rays and gamma rays (photons), neutrons (uncharged particles), beta-particles (or electrons), and alpha-particles (which are helium nuclei) (Linet, 1985) .

Alpha-particles (ionizing radiation of high linear-energy transfer) pass through tissue as highly structured tracks (Kadhim et al., 1994). Single target cells that are in the path of these tracks could be damaged even by low dose alpha-irradiation (Kadhim et al., 1994). Kadhim et al., 1994 have reported a high frequency of nonclonal cytogenetic abnormalities in the clonal descendants of low-dose alpha-irradiated murine hematopoietic stem cells 
that survived (Plutonium-238, an alpha-emitter, was used to irradiate the marine hematopoietic stem cells (Kadhim et al., 1992)). This data is compatible with alpha-particles inducing lesions in stem cells which result in transmission of chromosomal instability to their progeny (Kaahim et al., 1992 and Kadhim et al., 1994). Kadhim et al., 1994 wanted to know if human bone marrow stem cells could show similar instability.

The results from two subjects out of four hematologically normal individuals were quantitatively similar to those in Kadhim et al., 1992 murine cells, and demonstrates that alpha-particles can induce chromosomal instability in human bone marrow cells. There was no evidence of induced instability in samples from the other two donors which may reflect a genetic component. The inter-individual variation in the clonal analysis of the genotypes of these four people is more than likely due to similar genetically determined differences in the inducibility of chromosomal instability. Chromosomal instability, whether genetically determined or induced by low level alpha-particle irradiation, may produce genetic changes in hematopoietic stem cells of some humans that could contribute to the development of leukemia (Kadhim et al., 1994). 
Many radiosensitive mutant cell lines of $\mathrm{CHO}$ (Chinese hamster ovary) and V79 cells have been studied to see if there is a correlation between radiation induced DNA lesions and chromosomal aberrations. In the xrs mutants (deficient in DNA double strand break (DSB) repair) there is a correlation between the extent of the defect in repair and the frequencies of chromosomal aberrations induced by radiation. In the radiosensitive mutant $\mathrm{V}-\mathrm{C} 4$ (in which there is no detectable defect in DNA DSB repair) the frequencies of $\mathrm{X}$-ray induced aberrations are high compared to wild type V79 cells. But, after treatment with restriction endonucleases (which induces only DSB's) or fission neutrons (high LET radiation which induces a high proportion of DSB's in comparison to low LET radiation), the frequencies of aberrations are similar to V79. This indicates that $\mathrm{V}-\mathrm{C} 4$ cells are defective in the repair of lesions induced by $x$-rays other than DSBs. Although DSBs are the most important lesions that lead to chromosomal aberrations, in repair deficient mutants, radiation induced lesions besides DSBs can lead to chromosomal aberrations (Natarajan et al., 1993).

A clonal population of cells is defined as cells that arise from the mitotic division of a single somatic cell (Nowell, 1976 and Wainscoat and Fey, 1990). A complication 
in the analysis of clonality is that cells constituting a single clone are not necessarily genetically identical because clonal evolution could occur within such a population of cells (Wainscoat and Fey, 1990).

Tumor initiation occurs when an induced change in a single previously normal cell makes that cell "neoplastic" and provides it with a selective growth advantage over adjacent normal cells. Every so often, as a result of genetic instability in the expanding tumor population mutant cells are produced where nearly all the variants are eliminated either because of metabolic disadvantage or immunologic destruction. But, occasionally one of these variants has an additional selective advantage with respect to the original tumor cells and normal cells, and this mutant becomes the precursor of a new predominant subpopulation (Nowell, 1976).

It would appear that a tumor (or leukemia) could be at its lowest level of malignancy when only the primary karyotypic change (i.e., a primary translocation) is present. The appearance of additional chromosome translocations (secondary translocations) not only may be associated with the biologic progression of the tumor but could be the direct cause of the progression. Chromosomes of cancerous cells are unstable because the genome is 
unstable forming new translocations and aberrations all of the time. Because the additional cytogenetic changes in cancers at diagnosis are often complex and numerous, they not only mask the primary translocation but also may be indicative of a more advanced stage of the cancer in which tumors are diagnosed, and are therefore examined cytogenetically (Sandberg, 1990).

Searches for early specific changes should be directed toward human neoplasms that show the least evidence of genetic alteration based on chromosome studies. These include about half of human acute leukemias, having no demonstrable cytogenetic abnormality, and the few other tumors that have minimal and consistent cytogenetic rearrangements. There may be occasional instances where the first neoplastic event is visible at the chromosome level, and the best candidates appear to be the few tumor varieties where the same cytogenetic abnormality is present in the neoplastic cells in almost every case (e.g., the Philadelphia chromosome) (Nowell, 1976).

Loeb (1991) considers the relationships between mutation rates and cancer. At least two mutations are required to account for changes in chromosomes that are observed in certain human inherited diseases. An analysis of the literature indicates that the spontaneous mutation 
rate in cells is sufficient to account for a two mutation hypothesis for cancer initiation, but there are a larger number of mutations observed in many human tumors. The spontaneous mutation rate in cells is not sufficient to account for these observed multiple mutations. If these multiple mutations in tumors are causally associated with cancer and not just an accompaniment of it, then Loeb argues that an early step in tumor progression is one that induces a mutator phenotype. A mutation rate that is increased in tumors may be the basis for the multiple mutations that characterize many cancers. Mutations in genes that are required for chromosome stability may result in genetic instability and could contribute to the multiple mutations that are observed in tumors (Loeb, 1991).

The genetic stability of normal and neoplastic lymphocytes was compared by Seshadri et al., 1987 using a base-line mutation frequency as well as mutation rate/cell generation. Thioguanine-resistant cells were enumerated in a clonogenic assay to study mutations at the hypoxanthine-guanine phosphoribosyltransferase locus. Normal cells from three individuals and three malignant cell lines were used in this experiment. Based on chromosomal analysis, it has been suggested that maligant cells are genetically unstable. This instability could be the 
underlying mechanism in the development of cytotoxic drug resistance and tumor progression (Seshadri et al., 1987).

The three malignant cell lines had spontaneous in vitro mutation frequencies that were 10-to-1000-fold greater than the spontaneous in vivo mutation frequency of normal lymphocytes. The rate of mutation/cell/generation in malignant cells was 2-to-120-fold greater when compared with normal lymphocytes. The higher base-line mutation frequency and mutation cell/generation rate for the three malignant cell lines compared with normal lymphocytes suggest that neoplastic lymphocytes are more genetically unstable than normal lymphocytes (Seshadri et al., 1987).

Cifone and Fidler (1981) used cloned cells from three mouse tumors that had differing metastatic potential to determine the spontaneous mutation rates of cells with low or high metastatic capacities with respect to selective genetic markers. The genetic markers were 6-thiopurine resistance or ouabain resistance, or both. Cells with a high metastatic potential had a 3-to-7-fold increase in mutation rate (per cell generation) in all cases at both genetic loci compared to their low metastatic but tumorigenic cell controls. The hypothesis that evolution from benign to the malignant state of tumors may be the consequence of acquired genetic instability in neoplastic 
cells is supported by the results (Cifone and Fidler, 1981).

It is well established that human tumors, in particular the leukemias and lymphomas, are characterized by chromosomal abnormalities that are nonrandom. In the past two years, many proto-oncogenes and transforming genes have been mapped to chromosomal breakpoints that are involved in specific structural rearrangements. There is another factor that has added interest in chromosomal abnormalities that are cancer-specific. It is the recent recognition that breakpoints noted in recurring structural rearrangements in human tumors have a remarkable concordance with locations of heritable and common fragile sites. Several individuals who have malignant diseases (that are characterized by specific abnormalities) were identified as fragile site carriers at the point where a chromosome break occurred (Le Beau, 1986 and Hecht, 1988, pgs. 119-121).

A fragile site is a region of a chromosome, usually on both chromatids, that does not stain (Le Beau and Rowley, 1984, and Nancarrow et al., 1994). There has been a great flux back and forth in the thinking about cancer chromosome breakpoints and fragile sites (Hecht and Sandberg, 1988). Fragile sites were first reviewed as being far from cancer breakpoints (Hecht and Sandberg, 1988). Then, they were seen as associated with cancer breakpoints (Hecht and 
Sandberg, 1988). Now, it's going back towards the original view (Hecht and Sandberg, 1988).

\section{Research Goad}

The goal for this project is to evaluate a method of obtaining background frequencies for individuals with known translocations involved in clonal expansion. Two cases will be studied: (1) two healthy individuals who have never been exposed to ionizing radiation above background, chemotherapy or radiotherapy, and have never had cancer. These individuals do have clones involving translocations which elevate the background frequency for one of the healthy individuals (Bio 8) 2.638 times and the other healthy individual (Bio 23) 1.46 times; and (2) a patient who already has cancer, and thus clones. The cancer patient is in an early stage of B-precursor acute lymphocytic leukemia (ALL). Two methods of obtaining background translocation frequencies are investigated with these patients: (1) purging all clones from the data should bring the translocation frequencies closer to background frequencies if there hasn't been any exposure; and (2) measuring the translocation frequency using chromosomes that are not involved in the clones (no clonal expansion of cells with translocations so there will not be an artificially high 
translocation frequency) should represent the true translocation background frequency. With the leukemia patient, the measured background frequencies will be compared to that measured in a different tissue (unaffected by the cancer). The true background frequency is the latter measurement (Lucas et al., 1994).

In a preliminary study of the two unexposed normal individuals, both showing a high level of clones involving certain chromosomes, discounting these clones lowered the translocation frequency closer to expected values. A preliminary trend appears that a background frequency of translocations for these individuals can be obtained by discounting translocations that are clones. A complication of this approach could possibly be more than one clone of the same translocation. Since we are only looking at one translocation there could be clonal evolution/expansion with several clones evolved from the original and all carrying the same translocation.

The second case involves a nuclear dockyard worker with early B-precursor ALL. It was suspected that his leukemia was caused by exposure to uranium which produces ionizing radiation alpha-particles (Lucas et al., 1994 and Linet, 1985). As stated earlier, acute forms of leukemia (including acute lymphocytic leukemia as well as the 
subtypes of acute nonlymphocytic leukemia (ANLL)) and chronic myelocytic leukemia (CML) have been found to be induced by radiation (Linet, 1985).

A preliminary investigation showed that the unaffected $T$ lymphocyte translocation frequency is consistent with background, but the whole blood translocation frequency is much higher (Lucas et al., 1994). It is expected that whole blood metaphase spreads for the leukemia patient contain translocations involved in clones (or clonal expansion) which would artificially increase the translocation frequency. The significance of this study is that elimination of cloned translocations from the data should bring the level of translocation frequencies within background levels. 


\section{MDTHODS AND MATERIALS}

The Royal Marsden Hospital at London and Surrey obtained blood samples from the early B-precursor ALL patient and cryopreserved them (Lucas et al., 1994). These cryopreserved aliquots of leukapherized blood leukocytes from the leukemia patient were then used to make metaphase spreads of whole blood and separated $\mathrm{T}$ lymphocytes (Lucas et al., 1994). The procedure for separation of $T$ lymphocytes follows an established protocol (Lucas et al., 1994). These metaphase spreads were then sent to Dr. Joe Lucas for study.

After diagnosis of the disease, but before therapy, blood lymphocytes were obtained (Lucas et al., 1994). Measurements of the frequency of chromosomal abnormalities were made for phytohemagglutinin (PHA-M)-stimulated lymphocytes without separation of $T$ and $B$ cells as well as $T$ lymphocytes after complete separation of B cells (Lucas et al., 1994). So, there are slides from the early B-precursor ALI patient's separated unaffected $T$ lymphocytes and whole blood (unseparated B and $T$ lymphocytes) that were scored previously (Lucas et al., 1994). All metaphase spreads are scored (or counted) as normal if all the "painted" chromosomes have no aberrations (Lucas et al., 1992). Aberrations are scored as reciprocal translocations when two chromosomes are bi-colored and each have one centromere 
(Lucas et al., 1992). Aberrations are scored as dicentrics or acentric fragments if the chromosomes showed two or no centromeres (Lucas et al., 1992).

The accepted method for measurement of prior exposure to clastogenic agents involves the quantification of chromosomal aberrations in human blood lymphocytes derived from the thymus, which are $T$ lymphocytes. The approach is to get a small blood sample from the individual that is to be evaluated, stimulate the growth of $T$ lymphocytes using PHA-M (phytohemagglutinin), collect the cells in metaphase, spread these cells on slides, and count the number of aberrations seen in the metaphase chromosomes (Lucas et al., 1994)

This biodosimetic method works well when individuals that are evaluated do not have malignancies that involve the bone marrow or Iymphatic system. But, when these malignancies are present this method breaks down because the metaphase cells being evaluated have an unpredictable number of chromosomal abnormalities resulting from genetic instability of the cancer cells. Thus, aberrations induced by prior exposures may be masked. This is the case even if the malignancy is limited to B lymphocytes (bone marrowderived). PHA-M primarily stimulates $T$ lymphocytes but a fraction of B lymphocytes are also stimulated by PHA-M which 
contaminates the $T$ lymphocyte sample with cancer cells that are cytogenetically unstable. So, the separation of $\mathrm{T}$ cells before PHA stimulation is necessary to eliminate the cancer related chromosomal damage (Lucas et al., 1994).

The fluorescent in situ hybridization of metaphase chromosomes of both separated $T$ lymphocytes and whole blood from the early B-precursor ALL patient with whole chromosome probes follows an established protocol with some alterations (Lucas et al., 1989, pgs. 35-44, 1992, 1994, and straume and Lucas, 1993). The previously scored separated $T$ lymphocytes and all of the whole blood slides from the leukemia patient underwent pre-treatment. The rest of the scored separated $T$ lymphocyte slides from the leukemia patient did not require pre-treatment. The hybridization protocol for metaphase chromosomes of whole blood has modifications in pretreatment, hybridization, and washing of slides (Dr. Joe Lucas, 1995 unpublished) .

The modification for pre-treatment is that the slides are rinsed in $2 \times S S C$ (SSC is $0.15 \mathrm{M} \mathrm{NaCl} / 0.015 \mathrm{M}$ Na Citrate) that is at $\mathrm{pH} 6.3$. Usually it is at $\mathrm{pH} 7.0$.

Next is the modification for hybridization. The slides are denatured in a solution of $70 \%$ formamide and $2 \times S S C$ at $\mathrm{pH}$ 5.3 (instead of $\mathrm{pH} 7.0$ ) for five minutes at $70^{\circ} \mathrm{C}$. The slides are then warmed to $45^{\circ} \mathrm{C}$. The hybridization mixture 
is 7ul hybridization buffer (dextran sulfate, formamide, SSC ( $\mathrm{pH} 7.0)$ )(Vysis), 2uL of chromosome 1, 2 and 4 spectrum orange (Vysis) which is a directly labeled whole chromosome probe mixture for chromosomes 1,2 and 4 , and 1 uL sterile water which is denatured at $70^{\circ} \mathrm{C}$ for 5 minutes.

The last step is the washing of slides. The primary modification for this step is that the slides are washed in wash solutions \#1-3 (50\% formamide/2xSSC) at a pH of 5.3 instead of $\mathrm{pH} 7.0$ at $45^{\circ} \mathrm{C}$ for 10 minutes each. Next they are washed in wash solutions of $2 \times S S C$ pH 6.3 and then PN buffer $\mathrm{pH} 6.3$ (a mixture of $0.1 \mathrm{M} \mathrm{NaH2PO4}$ and $0.1 \mathrm{M} \mathrm{Na2HPO4}$ at $\mathrm{pH}$ 8.0, then adding drops of $\mathrm{HCl}$ to get $\mathrm{pH} 6.3$ ). Normally $2 * \mathrm{SSC}$ is $\mathrm{pH} 7.0$ and $\mathrm{PN}$ buffer is $\mathrm{pH} 8.0$. The slides are washed for 10 minutes at $45^{\circ} \mathrm{C}$ in $2 * \mathrm{SSC} \mathrm{pH} 6.3$ and $\mathrm{PN}$ buffer pH 6.3 for 5 minutes in wash solution \#5.

Aberration detection of metaphase spreads from the leukemia patient (both unseparated $B$ and $T$ lymphocytes and isolated unaffected $T$ lymphocytes) follows the standard protocol described by Lucas et al., 1992 and 1994. The following exception is that some of the metaphase spreads were directly labeled with a whole chromosome probe for chromosomes 1, 2 and 4 (Spectrum Orange (Vysis)) instead of an indirectly labeled whole chromosome probe for chromosomes 
1, 2 and 4 painted green.

Directly labeled whole chromosome probes contain chromosome specific DNA that is homologous to human sequences and blocking DNA to minimize hybridization to other chromosomes. For this experiment the whole chromosome probe is directly labeled with spectrum orange (Vysis) fluorophores (a fluorescent tag). After washing the slides that are hybridized with a directly labeled whole chromosome probe, the results are then viewed on a fluorescence microscope (Vysis, WCP Chromosome Painting system, Information Leaflet).

Indirectly labeled whole chromosome probes are DNA or RNA probes that are labeled with biotin or digoxygenin (for this experiment they are DNA probes that are labeled with biotin). Since they do not have attached fluorochromes, the probes are then immunochemically stained using an antibody to digoxygenin and antibodies to those antibodies or avidin and anti-avidin (an antibody to avidin) in the case of biotin (avidin binds to biotin). One of the antibodies used in the case of digoxygenin are fluorescently labeled. Avidin is fluorescently labeled and sometimes the antiavidin is fluorescently labeled as well. Then, the results can be viewed with a fluorescence microscope (Department of Cytochemistry and cytometry, University Leiden, Netherlands, 
1992)

Metaphase spreads of the healthy individuals with clones were scored with a direct whole chromosome probe for chromosomes 1, 2 and 4 (Spectrum orange (Vysis)). The other chromosomes were stained a blue color with DAPI $\left(4^{\prime}, 6-\right.$ diamino-2-phenylindole) counterstain.

The additional slides scored from the leukemia patient's whole blood as well as the additional slides from the leukemia patient's separated $T$ lymphocytes were directly labeled with a whole chromosome probe for chromosomes 1, 2 and 4 (Spectrum Orange (Vysis)). The other chromosomes were stained a blue color with DAPI counterstain.

The hybridized slides were then scored for chromosomal aberrations on a Nikon fluorescence microscope, and pictures were taken of translocations. Reciprocal translocations were examined to see if clones were present. The clones were identified by examining $35 \mathrm{~mm}$ slides of the translocations. If the chromosomes involved in the translocation were the same and the breakpoints on both chromosomes were the same in the metaphases being examined, then the translocations are considered clones. Any clones were then removed from the data set used to determine the background translocation frequency of each individual. 
As the clones were purged from the data, the frequency of translocations for specific chromosomes went down. This frequency was then compared with the frequency of translocations for a chromosome not involved with clones. 


\section{RESULTS}

The number of translocations and the translocation frequencies before and after purging clones from the data for Bio 8, Bio 23, and Bio 11 unseparated are shown in Table 1 and Table 2. Data for Bio 11 separated $T$ lymphocytes are shown in Table 2 .

The translocation frequency or translocations/cell (genomic) is calculated by dividing the number of reciprocal translocations by the number of metaphases multiplied by the fraction of translocations detected for the chromosomes that are spanned by hybridization probes ( $\mathrm{Dr}$. Joe Lucas, personal communication). The frequency of translocations per cell that is detected by hybridization, $F$, can be compared to the genomic frequency of translocations per cell detected by banding analysis, $F b$, by $F h=2 F s(1-f s) F b$, where $f s$ is equal to the fraction of the genome that is hybridized by probes (Lucas et al., 1989, pg. 201).

For both healthy individuals (Bio 8 and Bio 23) cells with translocations involving chromosome 2 were not clones, however, translocations involving chromosomes 1 and 4 were determined to be from clones. As shown in Table 1, the total reciprocal translocation frequency for both individuals is very high (compared to the expected background translocation frequency) when translocations that 
involve chromosomes 1 and 4 are included in the calculation. One would expect a frequency of 0.0045 translocations/cell for Bio 8 and 0.0055 translocations/cell for Bio 23. However, calculating the frequency of translocations involving only chromosome 2 for Bio 8 was $0.0061 \pm 0.00146$ and for Bio 23 it was $0.0047 \pm 0.0017$. Neither of the two frequencies calculated using only chromosome 2 (which is nonclonal) was signifigantly different from the expected background translocation frequencies for chromosome 2 (see Table 1).

Two values were calculated for translocation frequencies after clones were purged from the data. The first value included in the data set one reciprocal translocation in each clone (assumed to be the original translocation). The second value purged all clones from the data set (see Table 1 for these values for Bio 8 and Bio 23). For Bio 8 the difference from the first value is slightly significant from the expected background translocation frequency which is represented by the translocation frequency of chromosome 2. The second value falls within standard error for background. For Bio 23, both the first and second values of translocation frequencies after clones were purged from the data were within one standard error of the true background frequency, 
represented by the translocation frequency of chromosome 2 .

The data for the unseparated whole blood from the early B-precursor ALL patient (Bio 11) are presented in Table 2. The translocation frequencies are high which is expected because the cancer-related translocations are included in the translocation frequency.

The data for the separated $T$ lymphocytes from the early B-precursor ALL patient (Bio 11) are presented in Table 2. The frequency for reciprocal translocations of Bio 11 separated T lymphocytes was high, however, the study is still ongoing. The expected background frequency for an individual in the age group of $30-40$ years old is about 0.003 .

An example of a Bio 8 clone involving chromosome 1 is shown in figure 1. Figure 2 shows an example of a Bio 23 clone involving chromosome 1. An example of a Bio 11 clone involving chromosome 4 is shown in figure 3 . Each of the clones have the same breakpoint on the painted chromosome (either chromosome 1, 2 or 4) and the unpainted chromosomes. 
TABLE 1. Data for Bio 8 and Bio 23 (two healthy, unexposed individuals) in which the number of reciprocal translocations and reciprocal translocation frequencies involving chromosome 2 (which does not have clones) and chromosomes 1,2 and 4 are shown. Translocations involving chromosome 2 represent the true background frequency for both Bio 8 and Bio 23. As shown in the table, standard error intervals of the translocation frequencies overlap in values for chromosome 2 and chromosomes 1,2 and 4 except for the first value for Bio 8 chromosomes 1,2 and 4 and chromosome 2 for Bio 8 which is in a statistically grey area. 
TABLE 1. RECIPROCAL TRANBLOCATION FREQUENCIES FOR BIO 8 AND BIO 23.

\begin{tabular}{|c|c|c|c|c|c|}
\hline & \multicolumn{2}{|c|}{ BIO 23} & \multicolumn{2}{|c|}{ BIO 8} & \multirow{2}{*}{$\begin{array}{l}\text { Expected no. of } \\
\text { translocations and } \\
\text { frequency (trans/cell) }\end{array}$} \\
\hline & $\begin{array}{c}\text { Chromosome } \\
2\end{array}$ & $\begin{array}{c}\text { Chromosome } \\
1,2,4\end{array}$ & $\begin{array}{c}\text { Chromosome } \\
2\end{array}$ & $\begin{array}{c}\text { Chromosome } \\
1,2,4\end{array}$ & \\
\hline $\begin{array}{l}\text { No. of Reciprocal Translocations } \\
\text { (Recip. Trans.) }\end{array}$ & 8 & $p \star=0.0492$ & $\begin{array}{c}18 \\
p=0.48\end{array}$ & $p=8 * 10 \wedge-7$ & \multirow{2}{*}{$\begin{array}{l}\text { Bio } 8 \text { (chromosome } 2 \\
\text { only) }=13 \text { translo- } \\
\text { cations, or } 0.0045\end{array}$} \\
\hline $\begin{array}{l}\text { No. of Recip. Trans. (- Clones, First } \\
\text { Value)* }\end{array}$ & 8 & 26 & 18 & 59 & \\
\hline $\begin{array}{l}\text { No. of Recip. Trans. (- Clones, Second } \\
\text { Value) } \star \star\end{array}$ & 8 & $\stackrel{24}{p=0.77}$ & 18 & 48 & \multirow{2}{*}{$\begin{array}{l}\text { Bio } 23 \text { (chromosome } 2 \\
\text { only) }=9 \text { transloca- } \\
\text { tions, or } 0.0055\end{array}$} \\
\hline $\begin{array}{l}\text { Frequency of Recip. Trans.(Total With } \\
\text { Clones)(trans/cell) }\end{array}$ & $\begin{array}{c}0.0047 \pm \\
0.0017\end{array}$ & $\begin{array}{r}0.0073 \pm \\
0.0014\end{array}$ & $\begin{array}{r}0.0061 \pm \\
0.0015\end{array}$ & $\begin{array}{r}0.0124 \pm \\
0.0014\end{array}$ & \\
\hline $\begin{array}{l}\text { Frequency of Recip. Trans. (- Clones, } \\
\text { First Value)* (trans/cell) }\end{array}$ & $\begin{array}{c}0.0047 \pm \\
0.0017\end{array}$ & $\begin{array}{r}0.0065 \pm \\
0.0013\end{array}$ & $\begin{array}{r}0.0061 \pm \\
0.0015\end{array}$ & $\begin{array}{r}0.0093 \pm \\
0.0012\end{array}$ & $\begin{array}{l}\text { Bio } 8=29 \text { transloca- } \\
\text { tions, or } 0.0045\end{array}$ \\
\hline $\begin{array}{l}\text { Frequency of Recip. Trans. (- Clones, } \\
\text { Second Value)**(trans/cell) }\end{array}$ & $\begin{array}{c}0.0047 \pm \\
0.0017\end{array}$ & $\begin{array}{r}0.0060 \pm \\
0.0012\end{array}$ & $\begin{array}{r}0.0061 \pm \\
0.0015\end{array}$ & $\begin{array}{r}0.0075 \pm \\
0.0011\end{array}$ & $\begin{array}{l}\text { Bio } 23=22 \text { transloca- } \\
\text { tions, or } 0.0055\end{array}$ \\
\hline
\end{tabular}

First value* ${ }^{\star}$ - clones, counting one translocation in each clone (assumed the original translocation). Second value* ${ }^{*}$ - clones, purging all clones from the data.

The error used was standard deviation (one standard deviation equals one standard error)

No. of metaphases for Bio 23 is 11,342 or 1701 (chromosome 2 ) and 3970 (chromosome 1,2 and 4 ) full genomic equivalents.

No. of metaphases for Bio 8 is 19,492 (chromosome 2 only) and 18,198 (chromosome 1,2 and 4 ) or 2924 (chromosome 2) and 6369 (chromosome 1, 2 and 4) full genomic equivalents.

$p$ value test for significance between expected and measured number of translocations. pt = $p$ value test for significance between the no. of recip. trans. including clones and the second value for Bio 23 . 
TABLE 2. From the translocation frequencies (before and after purging of the clones) for Bio 11 unseparated whole blood of chromosomes 1, 2 and 4, one can see that these values are high. This may suggest an increase in the translocation frequency in these chromosomes which are not involved with the cancer. The translocation frequency for Bio 11 separated T lymphocytes is high as well, however, this study is ongoing. 
TABLE 2. RECIPROCAL TRANSLOCATION FREQUENCIES FOR BIO 11 UNBEPARATED WHOLE BLOOD AND BIO 11 SEPARATED T IYMPHOCYTES.

\begin{tabular}{|c|c|c|c|c|}
\hline & 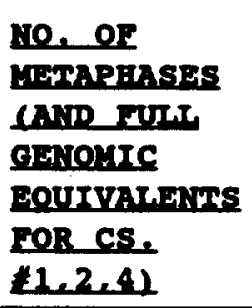 & $\begin{array}{l}\text { RECIP, TRANS. } \\
\text { EREOUMNCX } \\
(C S .11,2,4)\end{array}$ & $\begin{array}{l}\text { RECIP. } \\
\text { TRANS. } \\
\text { ERSOUHNCY } \\
\text { (CS.\#1,2,4) } \\
\text { (-CLONES. } \\
\text { EIRST } \\
\text { VALUE)* }\end{array}$ & $\begin{array}{l}\text { RECIP. TRANS. } \\
\text { EREOUFNCY } \\
\text { (CS \#1.2,4) } \\
\text { (-CLONES, } \\
\text { SECOND } \\
\text { YALUE) * }\end{array}$ \\
\hline $\begin{array}{l}\text { Bio } 11 \\
\text { Unsoparated }\end{array}$ & $\begin{array}{l}7299 \\
(2555)\end{array}$ & $0.010 \pm 0.002$ & $0.009 \pm 0.0019$ & $0.0082 \pm 0.0018$ \\
\hline $\begin{array}{l}\text { Bio } 11 \\
\text { separated }\end{array}$ & $\begin{array}{l}9343 \\
(3270)\end{array}$ & $0.0046 \pm 0.0012$ & $-\infty$ & ---- \\
\hline $\begin{array}{l}\text { Expected } \\
\text { Value For } \\
\text { Bio } 11\end{array}$ & $-\infty-$ & 0.003 & ---- & --- \\
\hline
\end{tabular}

First value* $=$ - clones, counting one translocation in each clone (assumed the original translocation).

Second value* = - clones, purging all clones from the data.

The error used was standard deviation (one standard deviation equals one standard error). 
RIGURE 1. Examples of two clones of translocations from a healthy, unexposed individual (Bio 8) are presented here. As shown in the photos, both translocations involve chromosome $I$ and have the same breakpoint $\left(q^{2}\right)$. The unpainted chromosome has the same breakpoint and proportions in both translocations based on DAPI staining. The photos on the left were taken through a triple band pass filter. The photos on the right are the same metaphases but taken through a DAPI filter using a Nikon fluorescence microscope. 

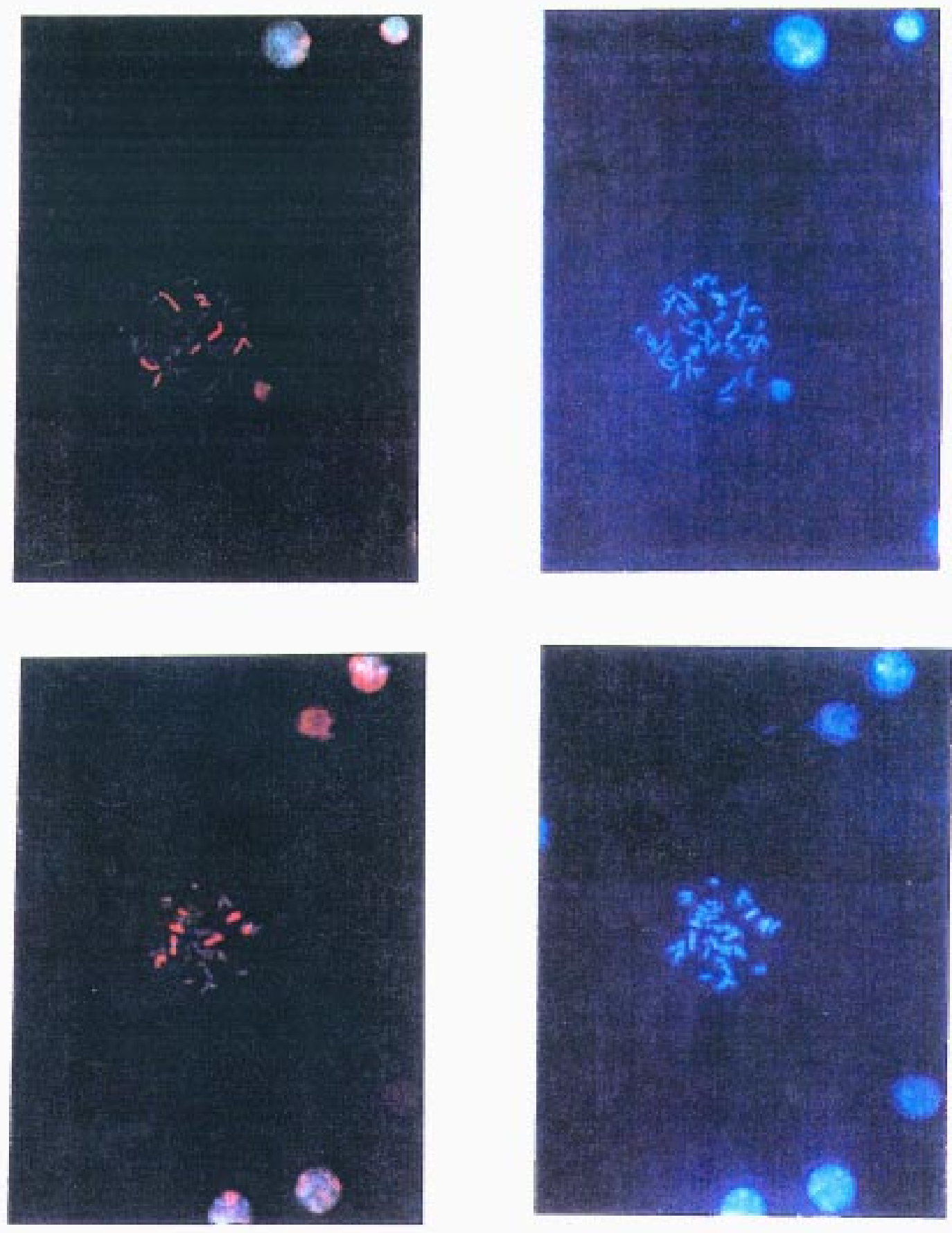
FIGURE 2. Examples of two clones of translocations from a healthy, unexposed individual (Bio 23) are presented here. Both translocations involve chromosome 1 and have the same breakpoint (q1). The unpainted chromosome has the same breakpoint and proportions in both translocations based on DAPI staining. The photos on the left were taken through a triple band pass filter. The photos on the right are the same metaphases but taken through a DAPI filter using a Nikon fluorescence microscope. 

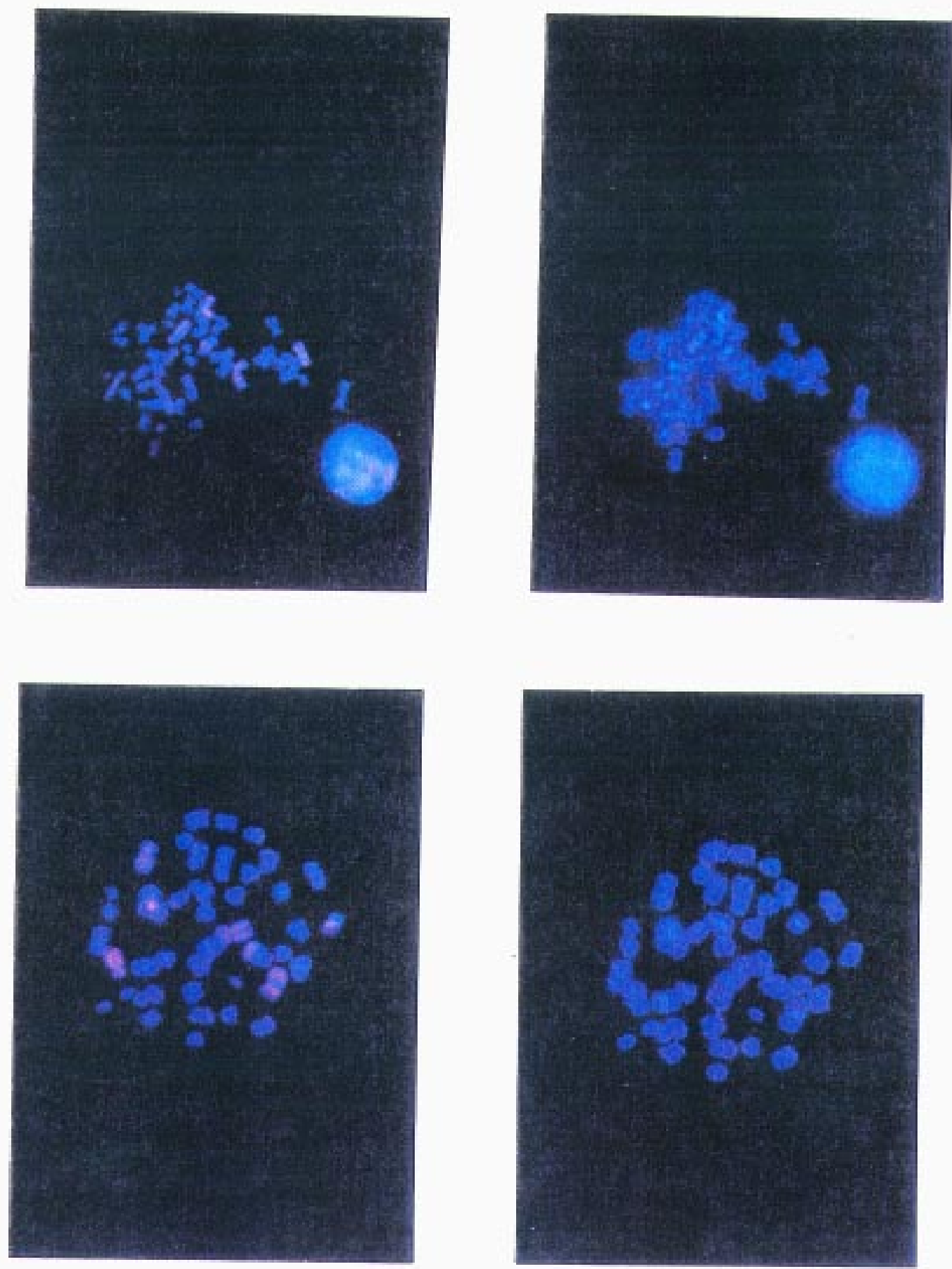
FIGURE 3. Examples of two clones of translocations from a leukemia patient (Bio 11 unseparated whole blood) are presented here. Both translocations involve chromosome 4 and have the same breakpoint (p1). The unpainted chromosome has the same breakpoint and proportions in both translocations based on DAPI staining. The photos on the left were taken through a triple band pass filter. The photos on the right are the same metaphase but taken through a DAPI filter using a Nikon fluorescence microscope. 

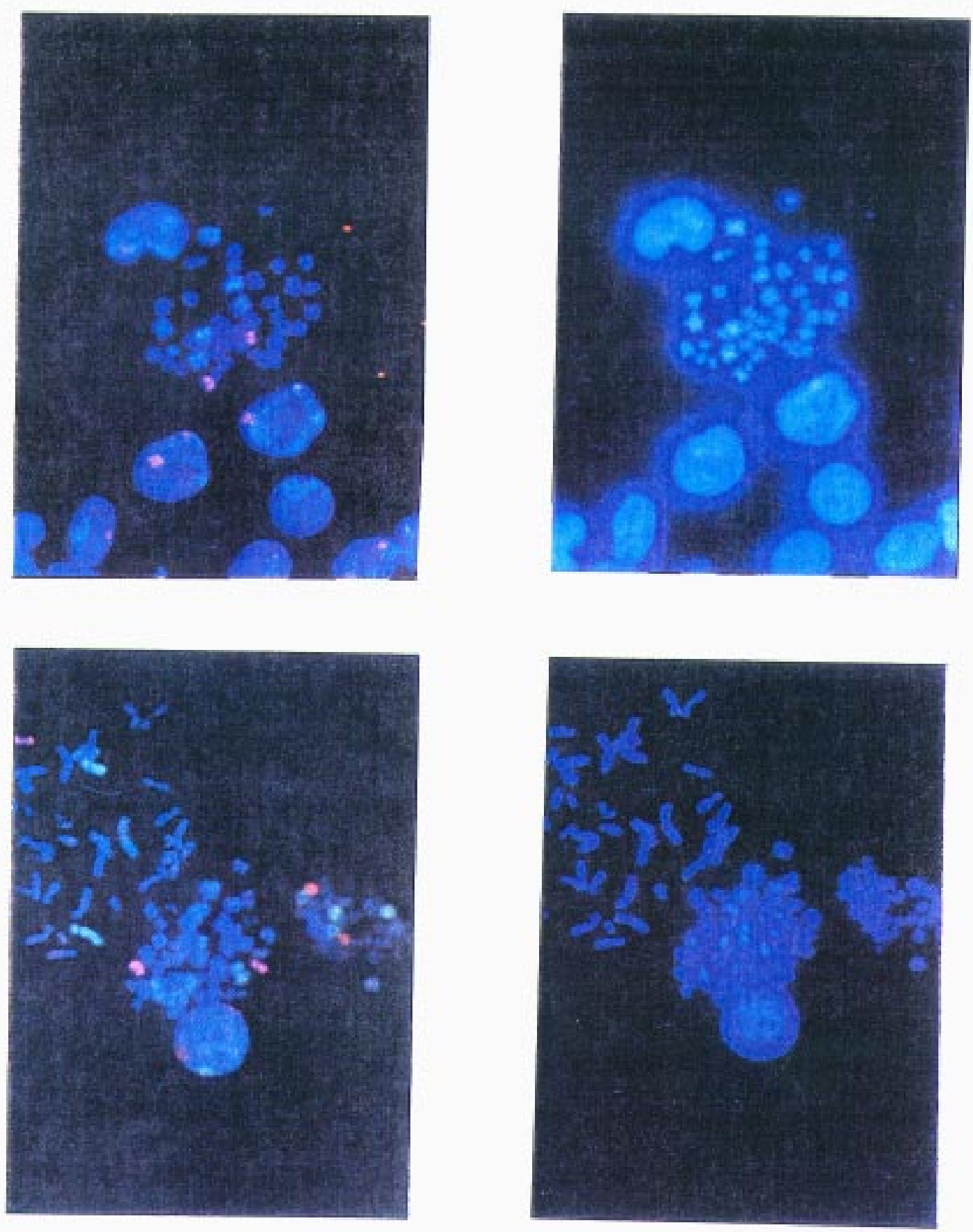


\section{DIscussion}

Two methods were proposed to measure background translocation frequencies: (1) purging clones from the data which should bring the translocation frequency closer to background translocation frequencies; and (2) measuring the translocation frequency using chromosomes not involved in clonal expansion which should represent the true translocation background frequency. For the leukemia patient, the measured translocation frequencies were compared to that measured in a different tissue (unaffected by the cancer) in which the true background frequency is the latter measurement (Lucas et al., 1994).

Methods 1 and 2 were applied to Bio 8 and Bio 23 where chromosome 2 was not involved in clonal expansion in both of these unexposed individuals. So, the true background frequency was represented by chromosome 2. After the clones were purged from the data for Bio 8 and Bio 23, all but one calculation was within standard error of the true background frequency (represented by chromosome 2 for both Bio 8 and Bio 23) (see Table 1). The translocation frequencies for Bio 8 chromosome 2 and chromosomes 1,2 and 4 (first value) did not overlap within standard error, however the difference is slightly significant (see Table 1). 
Method 1 was applied to Bio 11 (the early B-precursor ALL patient) and the true background frequency was measured in a different tissue (separated $T$ lymphocytes which are unaffected by the cancer). It was not represented by a chromosome (nonclonal) in the affected tissue (B cells). The translocation frequency for Bio 11 separated $T$ lymphocytes is high compared to expected background translocation frequencies (see Table 2). However, this study is still in progress. The translocation frequency for Bio 11 unseparated whole blood (containing B cells) is high even when clones are purged from the data (see Table 2). Three methods were used to analyze the data: (1) all reciprocal translocations were counted including the clones which makes the translocation frequency artificially high; (2) all clones but one translocation in each clone are purged from the data which lowers the translocation frequency closer to background; and (3) all clones are purged from the data which lowers the translocation even closer to background. There may be some error in the detection of clones if the translocations that are in a clone are low in frequency (clones involving translocations are low in number). clones involving translocations are easier to detect as the frequency of the clone increases. So, there may be one or a few clones that occur at a low 
frequency that are undetected, so that the number of clones may be underrepresented. There may be less error using the calculation of reciprocal translocations with the clones completely purged from the data. However, there could be clonal evolution/expansion as well with several clones evolved from the original and all carrying the same translocation.

Bio 11 separated $T$ lymphocytes (from the early Bprecursor ALL patient) had a higher translocation frequency than expected when compared to the background translocation frequency for a individual of 30-40 years of age (Lucas et al., 1994). The measurement of translocation frequencies and the background frequencies that have been recalculated are more accurate to date. However, this study is still in progress. The possibilities for the high translocation frequency of the Bio 11 separated $T$ lymphocytes could be that the leukemia may be affecting the $T$ lymphocytes or there was not a clean separation of $B$ cells from $T$ cells (which is unlikely).

The reciprocal translocation frequency for Bio 11 unseparated $B$ and $T$ lymphocytes is high even when clones are purged from the data (see Table 2). The high translocation frequency could be that some clones may be of low frequency and may not be recognized. Also, it could be that these 
cancer cells are unstable and are undergoing changes all the time. Therefore one would not be able to detect as many clones. It may be possible that if the leukemia was in a later stage, one may see many more clones at a higher frequency so that this method of obtaining background frequencies may be valid.

This method of obtaining background frequencies for individuals with known translocations involved in clonal expansion where clones are purged from the data appears to be valid. The standard error bars overlap when comparing the translocation frequency of chromosome 2 (the true background frequency) to chromosomes 1,2 and 4 (after clones were purged from the data, both first and second values in Table 1) for both Bio 8 and Bio 23. (Except the one calculation for Bio 8 mentioned in the beginning of the discussion which is slighly significant in difference). For Bio 8 and 23, there was no significant difference between the number of translocations scored for chromosome 2 and the expected number of translocations for chromosome 2 (see Table 1, $p$ values).

There are two ways to measure background frequency. one is by scoring a chromosome(s) where there is no clonal expansion. Second, is by scoring a chromosome(s) where there is clonal expansion, but the clones are purged from 
the data. As shown in Table 1, there is a significant difference between the number of reciprocal translocations including clones and the expected number of translocations, for example with Bio $8(p=8 * 10 \wedge-7)$. This shows the importance of purging clones from the data so that one will not have an artificially high background translocation frequency. One can also see that there is a significant difference between the number of reciprocal translocations including clones and the number of reciprocal translocations after all the clones are purged from the data, for example with Bio 23 (see Table 1, p value). 


\section{RFFFRFNCFS}

Bender, Michael A., Awa, Akio A., Brooks, Antone L., Evans, H. John, Groer, Peter G., Littlefield, L. Gayle, Pereira, Carlos, Preston, R. Julian, and Wachholz, Bruce W. (1988) Current Status of Cytogenetic Procedures to Detect and Quantify Previous Exposures to Radiation, Vol. 196, pp. 103-159.

Chen, Zhong, Morgan, Rodman, Berger, Carol S., Pierce-Birge, Lori, Stone, John F., and Sandberg, Avery A. (1993) Identification of Masked and Variant $\mathrm{Ph}$ (Complex Type) Translocations in CML and classic Ph in AML and ALL by Fluorescence In Situ Hybridization with the Use of bcr/abl Cosmid Probes, Cancer Genet. Cytogenet., Vol. 70, pp. 103-107.

Cifone, Maria A. and Fidler, Isaiah J. (1981) Increasing Metastatic Potential is Associated With Increasing Genetic Instability of Clones Isolated From Murine Neoplasms, Proc. Natl. Acad. Sci. USA, Vol. 78, No. 11, pp. 6949-6952.

Croce, Carlo M. (1987) Role of Chromosome Translocations in Human Neoplasia, Cell, Vol. 49, pp. 155-156.

Department of Cytochemistry and Cytometry, University of Leiden, The Netherlands; P. Lichter, German Cancer Research Center, Heidelberg, Germany and Ann Boyle, Yale University, New Haven, USA; J. Wienberg and $N$. Arnold, Institute for Anthropology and Human Genetics, University of Munich, Germany; S. Popp and T. Cremer, Institute for Human Genetics and Anthropology, University of Heidelberg, Germany; D.C. Ward, Human Genetics Department, Yale University, New Haven, Connecticut, USA (1992) In Situ Hybridization to Human Metaphase Chromosomes Using Digoxygenin- or BiotinLabeled DNA Probes and Detection With Fluorochrome Conjugates, Nonradioactive In situ Hybridization Application Manual, Boeringer Mannheim Biochemicals, Boeringer Mannheim GmbH Biochemica, pp. 25-30.

Dolphin, G.W., Lloyd, D.C., and Purrott, R.J. (1973) Chromosome Aberration Analysis as a Dosimetric Technique in Radiological Protection, Health Physics, Vol. 25, pp. 7-15. 
Evans, H.J., Buckton, K.E., Hamilton, G.E., and Carothers, A. (1979) Radiation-Induced Chromosome Aberrations in Nuclear-Dockyard Workers, Nature, Vol. 277, pp. 531534 .

Ferraris, Anna Maria, Canepa, Letizia, Massimo, Luisa, Dini, Giorgio, Broccia, Giorgio, Meloni, Tullio, Forteleoni, Gavino, Melani, Cecilia, and Gaetani, Gian Franco (1985) Clonal Development From a Progenitor with Restricted Differentiative Expression in Acute Lymphoblastic Leukemia, American Journal of Hematology, Vol. 20, pp. 81-83.

Harley, John H. (1983) Environmental Radioactivity-Natural, Proceedings of the Nineteenth Annual Meeting of the National Council on Radiation Protection and Measurements, Environmental Radioactivity, National Council on Radiation Protection and Measurements, Bethesda, Maryland, pp. 12-16.

Hecht, Frederick (1988) Editorial: The Fragile Site Hypothesis of Cancer, Cancer Genet. Cytogenet., Vol. 31, pp. 119-121.

Hecht, Frederick and Sandberg, Avery A. (1988) of Fragile Sites and Cancer Chromosome Breakpoints, Cancer Genet. Cytogenet., Vol. 31, pp. 1-3.

Kadhim, M.A., MacDonald, D.A., Goodhead, D.T., Lorimore, S.A., Marsden, S.J., and Wright, E.G. (1992) Transmission of Chromosomal Instability After Plutonium Alpha-Particle Irradiation, Nature, Vol. 355, pp. 738740 .

Kadhim, Munira A., Lorimore, Sally A., Hepburn, Mary D., Goodhead, Dudley T., Buckle, Veronica J. and Wright, Eric G., (1994) Alpha-Particle Induced Chromosomal Instability in Human Bone Marrow Cells, Lancet, Vol. 344, pp. 987-988.

Le Beau, Michelle M. (1986) Chromosomal Fragile sites and Cancer-Specific Rearrangements, Blood, Vol. 67, No.4, pp. 849-858.

Le Beau, Michelle M. and Rowley, Janet O. (1984) Heritable Fragile Sites in Cancer, Nature, Vol. 308, pp. 607608 . 
Linet, Martha S., M.D., M.P.H. (1985) Monographs in Epidemiology and Biostatistics Vol. 6, The Leukemias: Epidemiologic Aspects, Oxford University Press, New York, oxford, pp. 3-13, 123-184.

Loeb, Lawrence A. (1991) Mutator Phenotype May Be Required for Multistage Carcinogenesis, Cancer Res., Vol. 51, pp. 3075-3079.

Lucas, J.N., Swansbury, G., Clutterbuck, R., Hill, F., Burk, C. and straume, T. (1994) Discrimination Between Leukaemia and Non-Leukaemia-Related Chromosomal Abnormalities in the Patient's Lymphocytes, Int. J. Radiat. Biol., Vol. 66, No. 4, pp. 385-389.

Lucas, J.N., Hill, F., Burk, C., Fester, T. and Straume, T. (1995) Dose-Response Curve for Chromosome Translocations Measured in Human Lymphocytes Exposed to 60 Co Gamma Rays, Health Phys., Vol. 68, No. 6, pp. 761-765.

Lucas, J.N., Tenjin, T., Straume, T., Pinkel, D., Moore II, D. Litt, M., and Gray, J.W. (1989) Erratum, Int. J. Radiat. Biol., Vol. 56, No. 2, p. 201.

Lucas J.N., Personal Communication.

Lucas J.N. (1995) Protocol for Hybridization of Bio 11 slides With Whole Chromsome Probes, unpublished.

Lucas, J.N., Tenjin, T., Straume, T., Pinkel, D., Moore II, D. , Litt, M. and Gray, J.W. (1989) Rapid Human Chromosome Aberration Analysis Using Fluorescence In Situ Hybridization, Int. J. Radiat. Biol., Vol. 56, No. 1. pp. 35-44.

Lucas, J.N., Awa, A., Straume, T., Poggensee, M., Kodama, Y. Nakano, M., Ohtaki, K., Weier, H.-U., Pinkel, D., Gray, J. and Littlefield, G. (1992) Rapid Translocation Frequency Analysis in Humans Decades After Exposure to Ionizing Radiation, Int. J. Radiat. Biol., Vol. 62, No. 1. pp. 53-63.

Lucas, J.N., Hill, F.S., Burk, C.E., Cox, A.B., and straume, T. (1996) Stability of the Translocation Frequency Following Whole-Body Irradiation Measured in Rhesus Monkeys, Int. J. Radiat. Biol. (in press) 
Minden, Mark D. (1985) Stem Cells in Acute Leukemia, in: David W. Golde and Fumimaro Takaku (Eds.),

Hematopoietic stem Cells, Marcel Dekker, Inc., New York and Basel, pp. 273-289.

Nancarrow, J.K., Kremer, E., Holman, K. , Eyre, H., Doggett, N.A. LePaslier, D., Callen, D.F., Sutherland, G.R., and Richards, R.I. (1994) Implications of FRAl6A structure for the Mechanism of Chromosomal Fragile site Genesis, Science, Vol. 264, pp. 1938-1941.

Natarajan, A.T., Vyas, R.C., Darroudi, F., and Vermeulen, S. (1992) Frequencies of X-Ray-Induced Chromosome Translocations in Human Peripheral Lymphocytes as Detected by In Situ Hybridization Using ChromosomeSpecific DNA Libraries, Int. J. Radiat. Biol., Vol. 61, No. 2, pp. 199-203.

Natarajan, A.T., Darroudi, F., Jha, A.N., Meijers, M., and zdzienicka, M.Z. (1993) Ionizing Radiation Induced DNA Lesions Which Lead to Chromosomal Aberrations, Mutation Res., Vol. 299, pp. 297-303.

Nowell, Peter c. (1976) The Clonal Evolution of Tumor Cell Populations, Science, Vol. 194, pp. 23-28.

Pinkel, D., straume, T., and Gray, J.W. (1986) Cytogenetic Analysis Using Quantitative, High-Sensitivity, Fluorescence Hybridization, Proc. Natl. Acad. Sci. USA, Vol. 83, pp. 2934-2938.

Sandberg, Avery (1990) The Chromosomes in Human Cancer and Leukemia, Second Edition, Elsevier Science Publishing Co., Inc., New York, New York, pp. 772-781.

Savage, John R.K. and Simpson, Paul J. (1994) FISH "Painting" Patterns Resulting From Complex Exchanges, Mutation Res., Vol. 312, pp. 51-60.

Schmid, E., Zitzelsberger, H., Braselmann, H., Gray, J.W., and Bauchinger, M. (1992) Radiation-Induced Chromosome Aberrations Analysed by Fluorescence In Situ Hybridization with a Triple combination of composite Whole Chromosome-specific DNA Probes, Int. J. Radiat. Biol., Vol. 62, No. 6, pp. 673-678. 
Seshardri, Ram, Kutlaca, Robert J., Trainor, Kevin, Matthews, Chris and Morley, Alexander (1987) Mutation Rate of Normal and Malignant Human Lymphocytes, Cancer Res., Vol. 47, pp. 407-409.

Taniwaki, Masafumi, Speicher, Michael R., Lengauer, Christoph, Jauch, Anna, Popp, Susanne and Cremer, Thomas (1993) Characterization of Two Marker Chromosomes in a Patient with Acute Nonlymphocytic Leukemia by Two-Color Fluorescence In situ Hybridization, Cancer Genet. Cytogenet., Vol. 70, pp. 99-102.

Taniwaki, Masafumi, Nishida, Kazuhiro, Veda, Yutaka, Misawa, Shinichi, Nagai, Masami, Tagawa, Shinichi, Yamagami, Tamostu, Sugiyama, Haruo, Abe, Masafumi, Fukuhara, Shiro and Kashima, Kei (1995) Interphase and Metaphase Detection of the Breakpoint of $14 \mathrm{q} 32$ Translocation in B-Cell Malignancies by Double-Color Fluorescence In Situ Hybridization, Blood, Vol. 85, No. 11, pp. 32233228 .

Tucker, J.D., Ramsey, M.J., Lee, D.A. and Minkler, J.L. (1993) Validation of Chromosome Painting as a Biodosimeter in Human Peripheral Lymphocytes Following Acute Exposure to Ionizing Radiation In Vitro, Vol. 64, No. 1, pp. 27-37.

United Nations Environment Programme (1991) Geoffrey Lean (Ed.), in: Radiation: Doses, Effects, Risks, Blackwell Reference, oxford, U.K. and Cambridge, Massachusetts, pp. $11-30,65-84$.

Vrolijk, J., Sloos, W.C.R., Darroudi, F., Natarajan, A.T. and Tanke, H.J. (1994) A System for Fluorescence Metaphase Finding and scoring of Chromosomal Translocations visualized by In situ Hybridization, Int. J. Radiat. Biol., Vol. 66, No. 3, pp. 287-295.

Vysis, Chromosome Painting system, Information Leaflet.

Wainscoat, J.S. and Fey, M.F. (1990) Assessment in clonality in Human Tumors: A Review, Cancer Res., Vol. 50, pp. 1355-1360. 


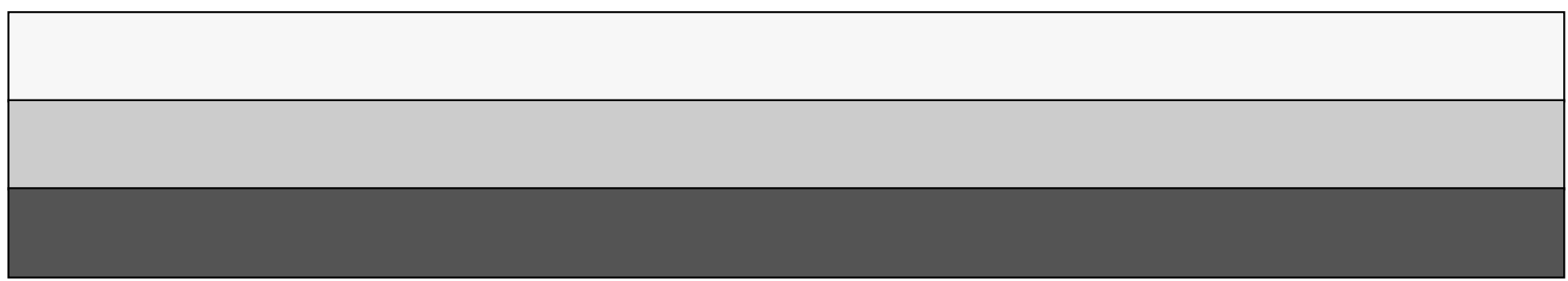

